\title{
The clinical significance and underlying correlation of pStat-3 and integrin av $\beta 6$ expression in gallbladder cancer
}

\author{
Liu Enyu ${ }^{1, *}$, Wang Na ${ }^{2, *}$, Zhao Chuanzong ${ }^{1}$, Wang Ben ${ }^{1}$, Wu Xiaojuan ${ }^{3}$, Wang Yan ${ }^{3}$, \\ Li Zequn ${ }^{1,4}$, Hong Jianguo ${ }^{1}$, Wang Jiayong ${ }^{1}$, Liang Benjia ${ }^{1,4}$, Peng Cheng ${ }^{1}$, Zhu Min ${ }^{1}$, \\ Zhang Zongli ${ }^{1}$

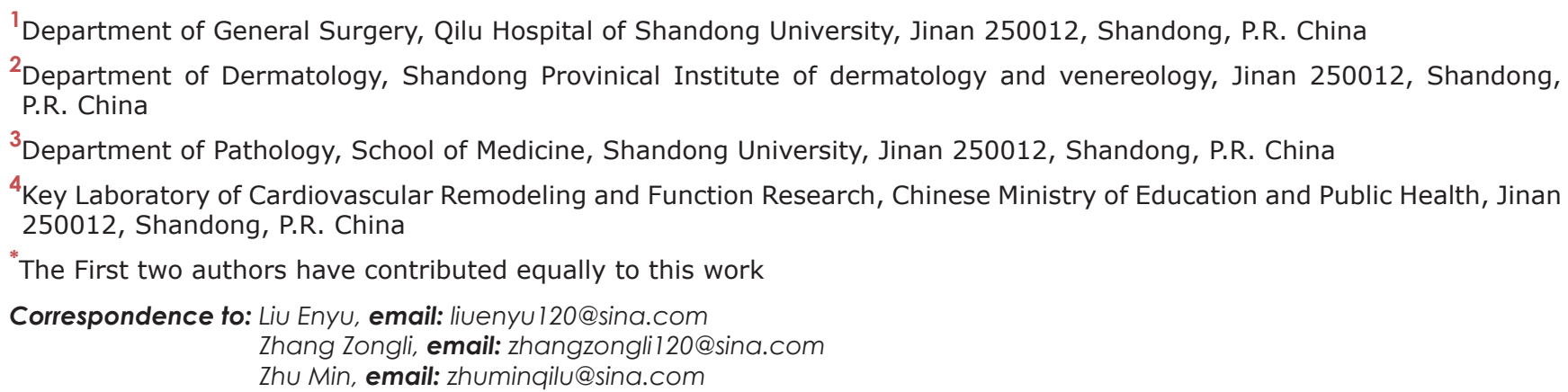

Keywords: gallbladder cancer, integrin $\beta 6$, pStat-3, immunohistochemistry, tumorigenesis

Received: April 28, $2016 \quad$ Accepted: November 01, 2016 Published: January 02, 2017

\section{ABSTRACT}

Background: Both phosphorylated signal transducer and activator of transcription 3 (pStat-3) and integrin av $\beta 6$ can play vital role in the development and progression of cancer. However, little is known about their expression correlation and clinical significance in gallbladder cancer(GBC).

Objective: The aim of our present study was to investigate the expression of pStat-3 and integrin av $\beta 6$, two proteins' correlation and their clinical significance in GBC tissues.xz

Results: The expression of pStat- 3 and integrin av $\beta 6$ were both significantly associated with $T$ stage, lymph node metastasis status, TNM stage $(P=0.008, P=0.000$, $P=0.000$ and $P=0.036, P=0.001, P=0.000$, respectively). IHC and Western blot showed their expressions in GBC tissues were higher than that in paraneoplastic tissues. Moderate positive correlation existed between the two proteins $(r=0.349, P<0.001)$. The survival analysis by Kaplan-Meier and Cox regression model showed that GBC patients with pStat- 3 or integrin av $\beta 6$ positive expression had a significantly poorer 2-year survival rate ( $P=0.002$ and 0.000 , the log-rank test, respectively), and either marker could act as unfavorable independent prognostic factors $(R R=1.907, P=0.021$ and $R R=2.046, P=0.038$ ).

Materials and Methods: The expression levels of pStat-3 and integrin av $\beta 6$ were analyzed in GBC cancerous and paraneoplastic tissues of 97 cases via immunohistochemistry(IHC) and further validated by western blot method. Besides, SPSS software was used to observe their clinical significance as well as the two proteins' correlation.

Conclusion: pStat-3 and integrin av $\beta 6$ were indicators of tumor's progression and poor prognosis of patients with GBC. And the further study involving them may provide a helpful therapeutic target in prevention and treatment of GBC patients. 


\section{INTRODUCTION}

Gallbladder cancer (GBC) is a highly aggressive malignant tumor of the biliary tract, which ranks fifth common among gastrointestinal cancers and accounts for $46 \%$ of biliary tract cancers in the United States [1]. Meanwhile the incidence rate of GBC is now increasing worldwide, with a rather poor prognosis [2]. However, most of these patients are diagnosed at an advanced stage lacking chances of radical surgery [3], and only about $10 \%$ were detected at early stage [4]. Therefore, it is important to explore underlying molecular mechanism of GBC for improve prognosis of GBC patients.

Generally known, long-term chronic inflammation predisposes tissue to cancer development in the process of GBC tumorigenesis [5-7]. Current studies have shown that signal transducer and activator of transcription 3 (STAT3) is a definitive link between inflammation and cancer transformation [8]. As a transcriptional factor, phosphorylation of STAT3 can subsequently promote transcriptions of target genes involving inflammation and malignancy. Consequently, persistent Stat3 target gene activation can stimulate cell growth, angiogenesis, metastasis, and anti-apoptosis, thereby driving and sustaining tumorigenesis [9-11].

Recent evidence has proved that STAT3 is involved in promoting transcription of integrin beta6 in oral squamous cell carcinoma and prostate epithelial cell caicinoma cells $[12,13]$. As is known, integrin families(24 members compromising of $18 \alpha$-subunits and $8 \beta$-subunit) can mediate cellular adhesion to extracellular matrix (ECM) and modulate diverse process such as cell proliferation, migration, invasion, and survival by activating intracellular signaling pathways [14-16]. Integrin $\beta 6$, with its sole binding partner $\alpha \mathrm{v}$ subunit, is an epithelial-cell-restricted antigen, which is expressed in tissue remodeling events (e.g., fibrosis, wound healing), as well as epithelial cancers (e.g., lung, breast, pancreas, ovary, oropharynx and colon) [17]. Integn $\alpha v \beta 6$ plays an vital role in various aspects of cancer progression and tissue repairing $[18,19]$.

However, the expression relationship of STAT3 and integrin $\alpha v \beta 6$ in gallbladder cancer, and their underlying interaction at molecular level have not been investigated before. The aim of our present study was to explore the expression and clinical significance of STAT3 combined with integrin $\alpha v \beta 6$ in GBC, which could provide a novel strategy for further study of molecular mechanism in therapeutic intervention.

\section{RESULTS}

\section{The expression of pStat-3 and integrin $\alpha v \beta 6$ in patients with gallbladder adenocarcinoma}

Immunohistochemistry results showed that pStat-3 was detected mainly in the nuclei, as well as in the cytoplasm. And integrinav $\beta 6$ was expressed both in cytoplasm and on cellular membrane. For pStat-3 expression, 59 of 97 cases with GBC could express pStat-3 in tumor tissue, with positive rate of $60.8 \%$, while 38 ones could not be stained as negative expression (Figure 1, Table 1). For integrin $\alpha v \beta 6$ patients, 44 of 97 cases $(45.4 \%)$ were positive

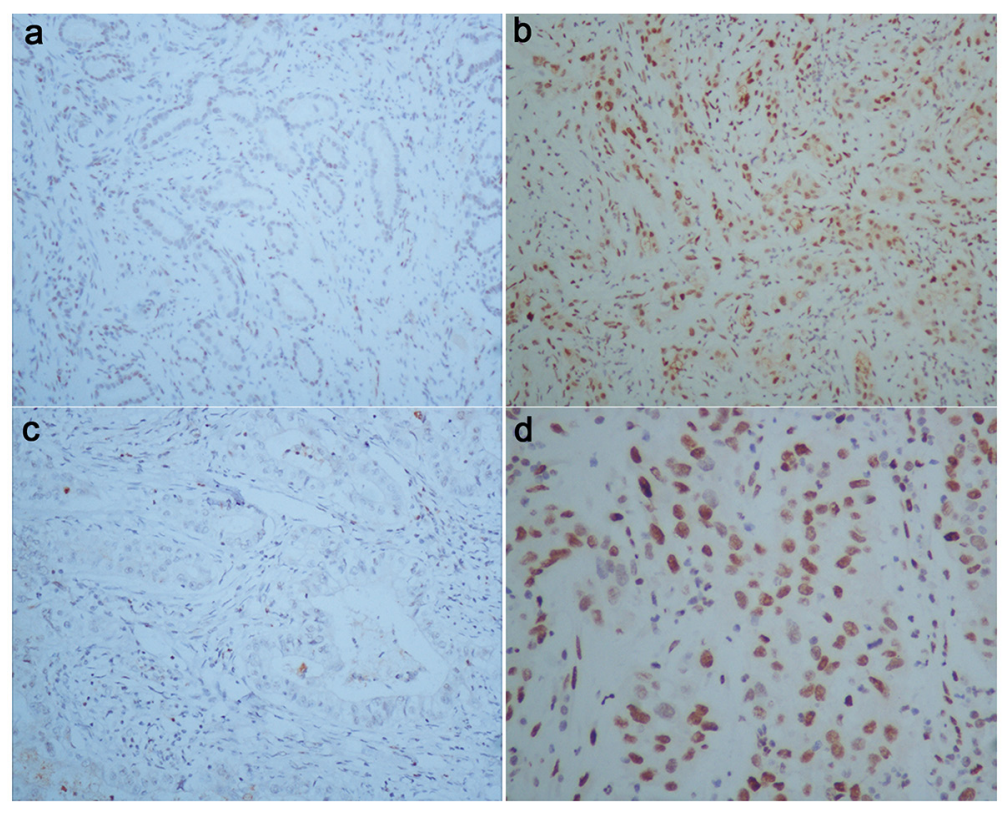

Figure 1: pStat-3 expression in human gallbladder carcinoma. First row: a, b. (Magnification $100 \mathrm{X}$ ); second row: c, d. corresponding to each figure above (Magnification $200 \mathrm{X}, 400 \mathrm{X}$, respectively). (a) and (c) were obtained from paracancerous normal tissue of patient with GBC, with negative staining. (b) and (d) were obtained from GBC tissue, with positive pStat-3 expression. 
Table 1: Association between pStat-3 expression, Integrinovß6 expression and clinicopathologic variables in gallbladder cancer patients

\begin{tabular}{|c|c|c|c|c|c|c|c|}
\hline \multirow{2}{*}{$\begin{array}{l}\text { Clinicopathological } \\
\text { factors }\end{array}$} & \multirow[t]{2}{*}{$\mathbf{n}$} & \multicolumn{2}{|c|}{ pStat-3 expression } & \multirow[t]{2}{*}{ P Value } & \multicolumn{2}{|c|}{ Integrin $\alpha v \beta 6$ expression } & \multirow[t]{2}{*}{ P Value } \\
\hline & & $\begin{array}{c}\text { Positive } \\
(\mathrm{n}=59)\end{array}$ & $\begin{array}{c}\text { Negative } \\
(n=38)\end{array}$ & & $\begin{array}{c}\text { Positive } \\
(n=44)\end{array}$ & $\begin{array}{c}\text { Negative } \\
(n=53)\end{array}$ & \\
\hline Gender & & & & 0.565 & & & 0.271 \\
\hline Male & 34 & 22 & 12 & & 18 & 16 & \\
\hline Female & 63 & 37 & 26 & & 26 & 37 & \\
\hline Age(years) & & & & 0.577 & & & 0.426 \\
\hline$<60$ & 35 & 20 & 15 & & 14 & 21 & \\
\hline$>=60$ & 62 & 39 & 23 & & 30 & 32 & \\
\hline T stage & & & & $0.008^{\#}$ & & & $0.036^{\#}$ \\
\hline $\mathrm{T} 1$ & 9 & 3 & 6 & & 4 & 5 & \\
\hline $\mathrm{T} 2$ & 43 & 23 & 20 & & 13 & 30 & \\
\hline $\mathrm{T} 3$ & 35 & 23 & 12 & & 20 & 15 & \\
\hline $\mathrm{T} 4$ & 10 & 10 & 0 & & 7 & 3 & \\
\hline $\begin{array}{l}\text { Lymph node } \\
\text { metastasis }\end{array}$ & & & & 0.000 & & & 0.001 \\
\hline yes & 36 & 30 & 6 & & 30 & 6 & \\
\hline no & 61 & 29 & 32 & & 14 & 47 & \\
\hline TNM stage & & & & $0.000^{\#}$ & & & $0.000^{\#}$ \\
\hline I & 6 & 1 & 5 & & 1 & 5 & \\
\hline II & 26 & 7 & 19 & & 1 & 25 & \\
\hline III & 48 & 35 & 13 & & 30 & 18 & \\
\hline IV & 17 & 16 & 1 & & 12 & 5 & \\
\hline Differentiation & & & & 0.778 & & & 0.268 \\
\hline well & 46 & 26 & 20 & & 17 & 29 & \\
\hline moderate & 37 & 24 & 13 & & 19 & 18 & \\
\hline $\begin{array}{l}\text { Poor/ } \\
\text { undifferentiated }\end{array}$ & 14 & 9 & 5 & & 8 & 6 & \\
\hline Gallstone & & & & 0.147 & & & 0.423 \\
\hline No & 55 & 30 & 25 & & 23 & 32 & \\
\hline Yes & 42 & 29 & 13 & & 21 & 21 & \\
\hline Pathological type & & & & 0.117 & & & 0.336 \\
\hline adenocarcinoma & 79 & 45 & 34 & & 34 & 45 & \\
\hline $\begin{array}{l}\text { Squamous/ } \\
\text { adenosquamous } \\
\text { carcinoma }\end{array}$ & 18 & 14 & 4 & & 10 & 8 & \\
\hline $\begin{array}{l}\text { Survival (24-month } \\
\text { follow-up) }\end{array}$ & & & & $0.002 *$ & & & $0.000 *$ \\
\hline
\end{tabular}

(Continued) 


\begin{tabular}{|c|c|c|c|c|c|c|c|}
\hline \multirow{2}{*}{$\begin{array}{l}\text { Clinicopathological } \\
\text { factors }\end{array}$} & \multirow[t]{2}{*}{$\mathbf{n}$} & \multicolumn{2}{|c|}{ pStat-3 expression } & \multirow[t]{2}{*}{ P Value } & \multicolumn{2}{|c|}{ Integrin $\alpha v \beta 6$ expression } & \multirow[t]{2}{*}{ P Value } \\
\hline & & $\begin{array}{l}\text { Positive } \\
(n=59)\end{array}$ & $\begin{array}{l}\text { Negative } \\
(n=38)\end{array}$ & & $\begin{array}{c}\text { Positive } \\
(n=44)\end{array}$ & $\begin{array}{l}\text { Negative } \\
(n=53)\end{array}$ & \\
\hline death & 79 & 52 & 27 & & 37 & 42 & \\
\hline censored & 18 & 7 & 11 & & 7 & 11 & \\
\hline
\end{tabular}

* Log-rank test; \# Fisher's Exact Test

expression, and 53 were negative (Figure 2, Table 1). And in the normal peritumoral tissues for the two markers were all negative staining $(\mathrm{P}<0.001)$. Moreover, we could find only 5 pStat- 3 positive expression and 2 integrin $\alpha v \beta 6$ positive expression exsiting in chronic cholecystitis tissues of 36 patients, significantly lower than that in tumor tissues.

Furthermore, we performed western blot analysis to validate the expression of $\alpha v \beta 6$ and pStat- 3 in GBC tissue, we performed western blot analysis in 10 paired primary tumor tissue and corresponding paracancerous nontumorous tissue, which indicated the expression of both proteins in 6 tumor tissues were significantly higher than that in their corresponding normal tissues among all the $10 \mathrm{GBC}$ patients, as shown in Figure 2.

\section{Correlations of pStat-3 and integrinav $\beta 6$ expression with clinicopathologic features of gallbladder adenocarcinoma}

pStat-3 positive staining is significantly higher in advanced $\mathrm{T}$ stage and TNM stages $(\mathrm{P}=0.008, \mathrm{P}=0.000$, respectively). Meanwhile, lymph node metastasis also affected pStat-3 staining, the pStat-3 positive rate of specimens with lymph node metastasis was $83.3 \%$, much higher than that of no lymph node metastasis group $47.5 \%(\mathrm{P}=0.000)$. As for integrin $\alpha v \beta 6$, significant association also existed between positive integrin $\alpha v \beta 6$ expression and advanced $\mathrm{T}$ stage $(\mathrm{P}=0.036)$, TNM stage $(\mathrm{P}=0.000)$, as well as lymph node metastasis status $(\mathrm{P}=0.001)$. However, there was no significant association among pStat-3 expression, patients' gender and age, pathological grade and type, and gallstone status, which was similar in patients' integrin $\alpha \mathrm{v} \beta 6$ expression. The detailed clinicopathologic data for pStat-3 and integrin $\alpha v \beta 6$ are outlined in Table 1.

\section{pStat-3 or integrinavß6 expression and the survival of patients with GBC}

All the 97 patients with gallbladder carcinoma were followed up for 24 month follow-up was conducted after surgery through email or phones. Kaplan-Meier survival analysis showed that patients with positive pStat-3 or integrin $\alpha v \beta 6$ expression had a significantly poorer overall survival than those with negative expression
$(\mathrm{P}=0.002, \mathrm{P}=0.000$, The log-rank test, respectively). Patients' survival over time on pStat-3 or integrin $\alpha v \beta 6$ expression is illustrated in Figure 3 and Figure 4.

\section{The correlation between integrinav $\beta 6$ and pStat-3 expression in patients with GBC}

As shown in Table 2, 35 of 44 patients(79.5\%) with positive integrin $\alpha \mathrm{v} \beta 6$ expression was observed in positive pStat-3 expression tissue, while 29 of 53 patients(54.7\%) with negative integrin $\alpha v \beta 6$ expression existed in negative pStat-3 expression tissue. According to the Spearman correlation analysis, integrin $\alpha v \beta 6$ expression had a moderate positive correlation with pStat-3 expression in patients with $\mathrm{GBC}(\mathrm{r}=0.349, \mathrm{P}<0.001$, Table 2$)$.

These 97 cases with GBC were classified into 4 groups according to integrin $\alpha v \beta 6$ and pStat- 3 expression, as follows: Group 1 with pStat-3(-) / integrin $\alpha v \beta 6(-)$ $(\mathrm{n}=29)$; Group 2 with pStat-3(-) / integrinav $\beta 6(+)(\mathrm{n}=9)$; Group 3 with pStat-3(+) / integrin $\alpha v \beta 6(-)(\mathrm{n}=24)$; and Group 4, pStat-3(+)/integrinav $\beta 6(+)(\mathrm{n}=35)$. Patients with $\mathrm{pStat}-3(+) /$ integrin $\alpha \mathrm{v} \beta 6(+)$ had a significantly poorer overall survival rate than other groups $(\mathrm{P}=0.000$, The logrank test), which is illustrated in Figure 5.

\section{Univariate and multivariate analysis for prognosis of patients with gallbladder cancer}

Cox proportional hazards regression model was applied to perform univariate and multivariate analyses to determine the prognostic value of clinicopathologic factors, pStat-3 and integrin $\alpha v \beta 6$ expression. In univariate analysis, positive expression of pStat- 3 and $\alpha v \beta 6$, plus advanced T stage, lymph node metastasis status and TNM stage could predict a poorer prognosis $(\mathrm{P}=0.004, \mathrm{P}=0.001, \mathrm{P}=0.028$, $\mathrm{P}=0.002, \mathrm{P}=0.011$, respectively)(Shown in Table 3). Next, these variables with $\mathrm{P}<0.05$ were collected for multivariate analysis, results revealed that positive pStat- 3 andav $\beta 6$ expression were unfavorable independent prognostic factors for patients with $\mathrm{GBC}$ (relative risk (RR): 1.907 and 2.046; $\mathrm{P}=0.021$ and 0.038 ,respectively) (Shown in Table 3 ).

\section{DISCUSSION}

Gallbladder cancer is a very aggressive malignant tumor with rising incidence and poor clinical outcome 


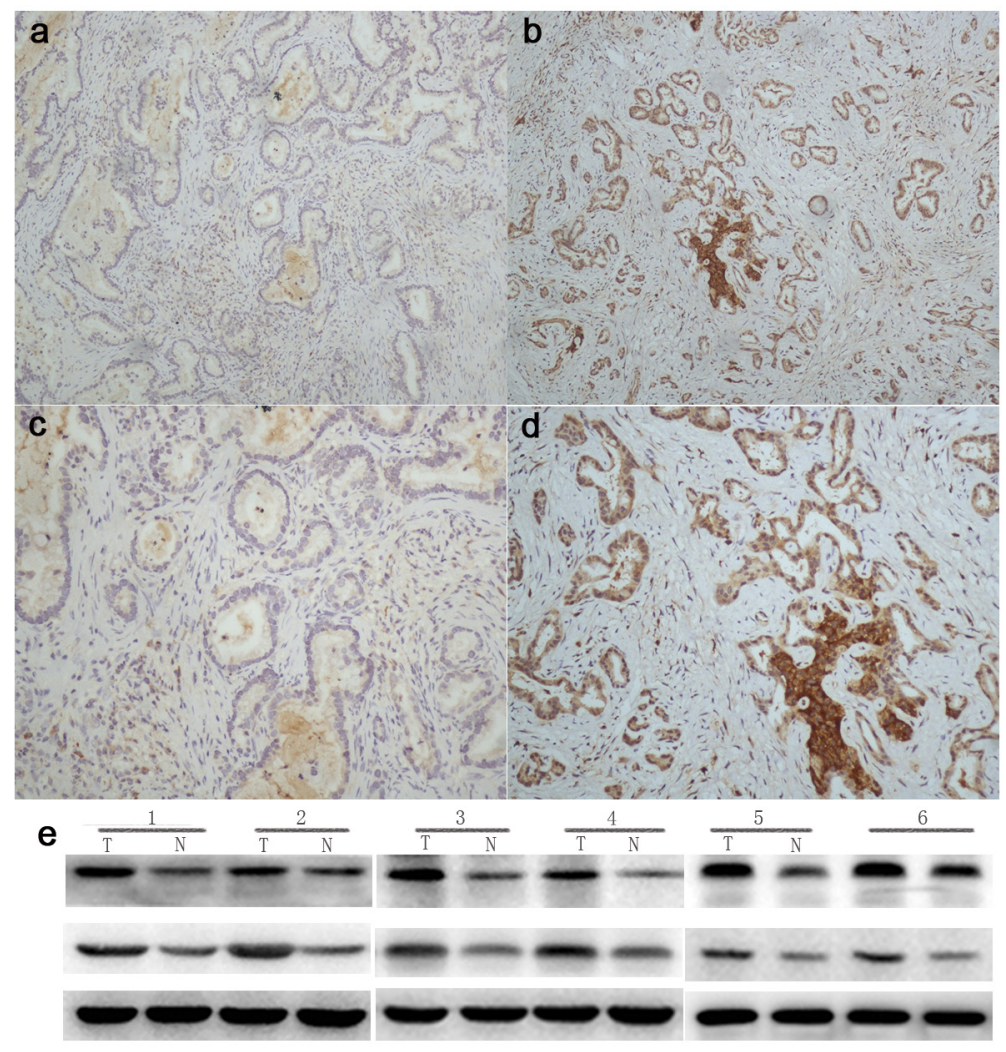

Figure 2: Integrin $\beta 6$ expression in human gallbladder carcinoma. First row: a, b. (Magnification $100 \mathrm{X}$ ); second row: c, d. (Magnification $200 \mathrm{X}$ ). (a) and (c). were obtained from paracancerous normal tissue of patient with GBC, with negative staining. (b) and (d). were obtained from GBC tissue, with negative integrin $\beta 6$ expression. e. To further validate the expression of $\alpha \mathrm{v} \beta 6$ and pStat-3 in GBC, we performed western blot analysis, which indicated the expression of both proteins in tumor tissues were significantly higher than that in corresponding paracancerous normal tissue.

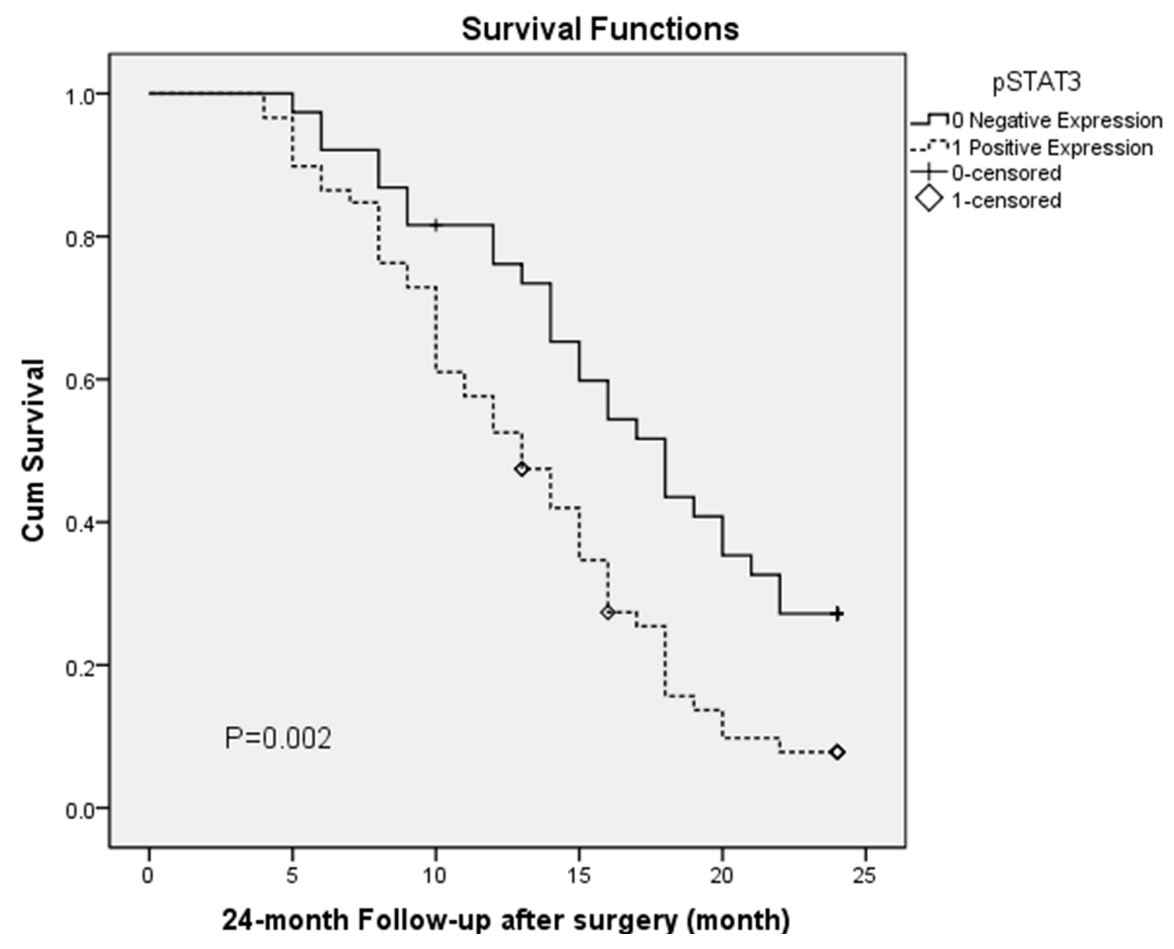

Figure 3: Overall survival according to pStat-3 expression $(P=0.002$, The log-rank test). 
Table 2: Correlation between integrinav $\beta 6$ expression and pStat-3 expression in human gallbladder carcinoma tissues (Spearman correlation, $r=0.349, \mathrm{P}<0.001)$

\begin{tabular}{lcccc}
\hline pStat-3 & \multicolumn{3}{c}{ integrin $\boldsymbol{\alpha v \beta 6}$} & total \\
\cline { 2 - 4 } & Positive & Negative & 59 \\
\hline Positive & 35 & 24 & 38 \\
Negative & 9 & 29 & 53 & 97 \\
total & 44 & 53 & \\
\hline
\end{tabular}

[20]. Despite improvements made in diagnosis and treatments during the past years, the prognosis of GBC remains extremely unsatisfactory [2, 5]. Therefore, understanding and exploring the molecular mechanism of tumorigenesis is in urgency, which would contribute to treatment of patients with this disease. In our present study, the positive expression of pSTAT- 3 and integrin $\alpha v \beta 6$ were observed via IHC staining and Western blot method in GBC samples. And we found that both p-STAT3 and integrin $\alpha \mathrm{v} \beta 6$ expression were significantly correlated with clinicopathological features and survival time for patients with GBC.
As is reported, integrin $\alpha \mathrm{v} \beta 6$ could be expressed in many epithelial cancers, including lung, breast, pancreas, ovary, oropharynx and colon cancers, as well as during tissue remodeling events such as fibrosis and wound healing [21, 22]. However, the expression of integrin $\alpha v \beta 6$ in GBC has never been investigated before. In this study, for the first time, we found that integrin $\alpha v \beta 6$ could be expressed in GBC cancerous tissues, and the expression rate was $45.4 \%$. Also, our results showed that its expression were significantly associated with clinical TNM stage, lymph node metastasis and the depth of invasion of tumors. According to the Cox

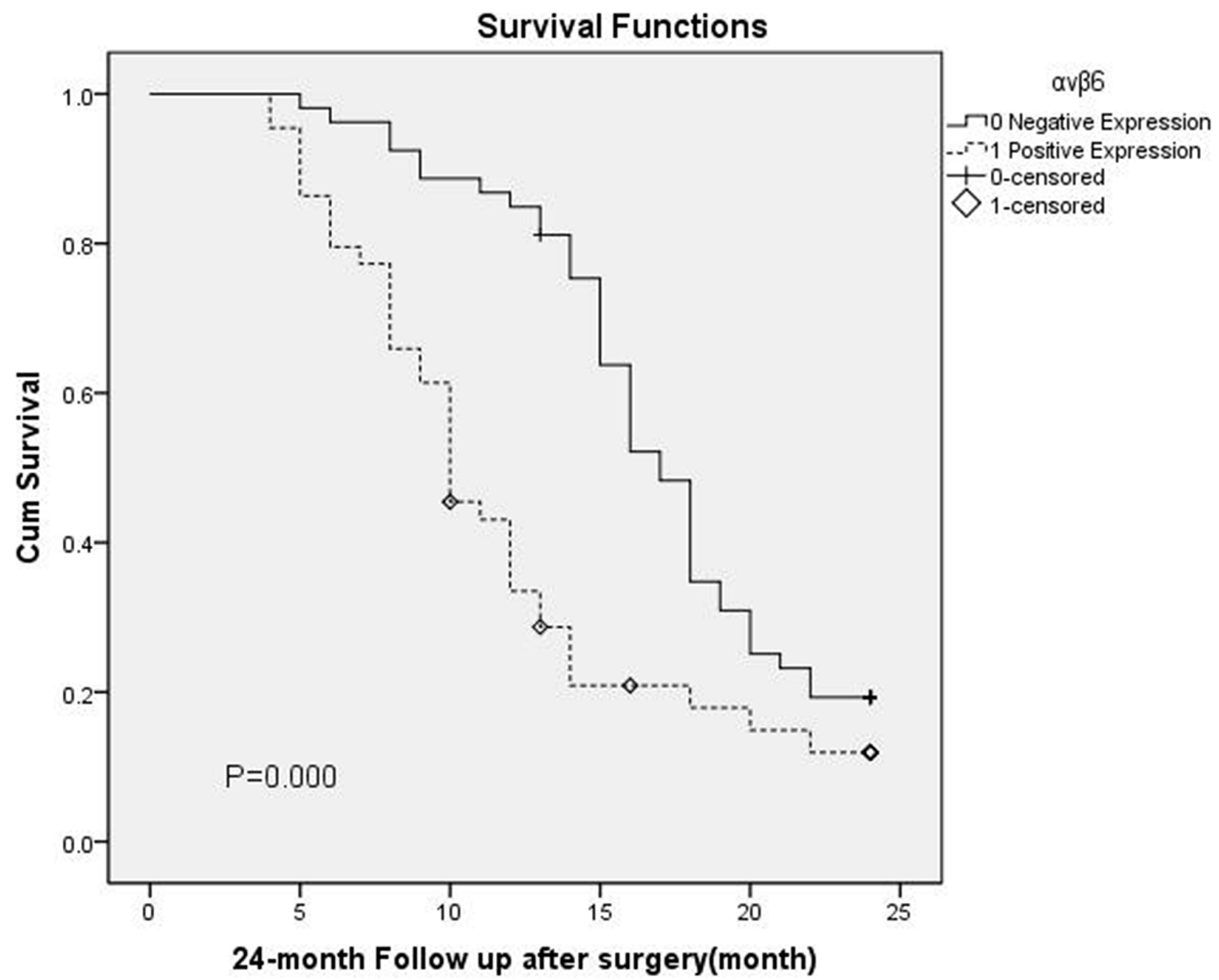

Figure 4: Overall survival according to $\alpha v \beta 6$ expression $(P=0.000$, The log-rank test $)$ 
regression model and survival analysis, we could prove that integrin $\alpha v \beta 6$ predicted a poor prognosis for GBC patients, the same as shown in patients with colonic and gastric carcinomas. We have previously shown a direct linkage between ERK2 and the cytoplasmic domain of $\beta 6$, through which the increasing phosphorylation of ERK2 could effectively contribute to the activation of downstream targets, involved in regulation of cellular invasion, metastasis, anti-apoptosis, chemo resistance and degradation of extracellular matrix by mediating MMP-9 secretion [23-26].

In present study, we first found p-Stat3 was obviously expressed in cancerous tissue of $\mathrm{GBC}$, and its expression was also significantly associated with clinical TNM stage, T stage and lymph node metastasis. And the Cox regression model and survival analysis showed that pStat could also predict a poor prognosis for GBC patients. As a transcriptional factor, STAT3 can be activated through phosphorylation at tyrosine 705 (Y705) and serine 727 (S727) by inflammatory cytokines driven signaling including interleukin-6(IL-6), IL-10, IL-17, IL21, IL-23, and vascular endothelial growth factor [27]. And phosphorylation of STAT3 can subsequently promote transcriptions of target genes involving inflammation and malignancy, such as Bcl-2, Bcl-xL, Mcl-1, Fas, cyclin D1, c-myc, VEGF, HIF-1, TGF $\beta$, and TIMP-1, etc [28]. Normally, Stat3 is activated in a transient manner, while it can be constitutively activated in long-term inflammatory and cancerous cells [8]. As a result, persistent Stat3 target gene activation can promote tumor development and sustain tumorigenesis [29].

Importantly, in this study, we found moderate positive correlation exists between $\mathrm{p}$-Stat 3 and integrin $\alpha v \beta 6$ by Spearman correlation analysis. To some extent, it demonstrated that certain interaction and relationship exist between protein expression levels of the two genes. This result is just in line with recent evidence that ITGB6 promoter contains a functional TATA box located -289 to -150 and that is binding sites for transcription factors STAT3 in oral squamous cell carcinoma cells [12]. Namely, integrin beta6 was downstream target genes of STAT3, which was involved in positive regulation of integrin beta6 transcription. In fact, integrin beta6 expression could be primarily regulated at the level of transcription initiation [30, 31], as well as at translational level [32]. It has been reported that under certain conditions, transcription factors including

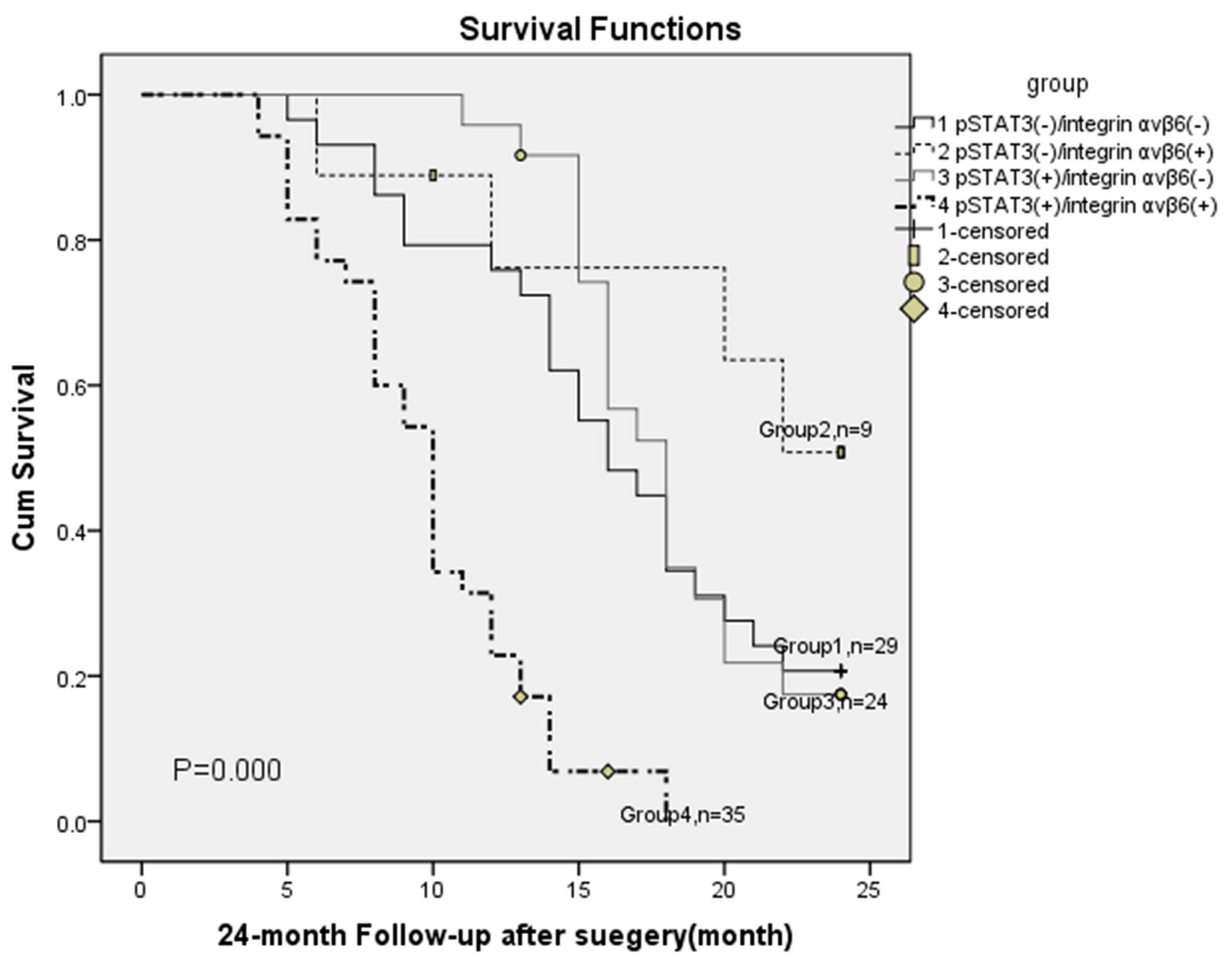

Figure 5: Overall survival according to $p S t a t-3$ with integrin $\alpha v \beta 6$ expression $(P=0.028$, The log-rank test $)$ 
Table 3: Univariate and multivariate analysis of association of clinicopathologic features with survival of GBC patients

\begin{tabular}{|c|c|c|c|c|c|c|}
\hline \multirow[t]{2}{*}{ Variable } & \multicolumn{3}{|c|}{ Univariate Analysis } & \multicolumn{3}{|c|}{ Multivariate Analysis } \\
\hline & Relative Risk & $95 \%$ CI & P Value & Relative Risk & $95 \% \mathrm{CI}$ & P Value \\
\hline Age at Diagnosis & 0.978 & $0.950,1.007$ & 0.137 & & & \\
\hline \multicolumn{7}{|l|}{ gender } \\
\hline Male & 1.000 (Ref.) & - & - & & & \\
\hline Female & 1.311 & $0.810,2.122$ & 0.270 & & & \\
\hline T stage & & & 0.028 & & & 0.487 \\
\hline $\mathrm{T} 1$ & 1.000 (Ref.) & - & - & 1.000 (Ref.) & - & - \\
\hline $\mathrm{T} 2$ & 2.673 & $0.948,7.532$ & 0.063 & 1.610 & $0.447,5.797$ & 0.466 \\
\hline $\mathrm{T} 3$ & 4.287 & $1.502,12.236$ & 0.007 & 2.500 & $0.685,9.126$ & 0.166 \\
\hline $\mathrm{T} 4$ & 3.652 & $1.092,12.217$ & 0.036 & 2.297 & $0.424,12.456$ & 0.335 \\
\hline \multicolumn{7}{|l|}{$\begin{array}{l}\text { Lymph node } \\
\text { metastasis }\end{array}$} \\
\hline no & 1.000 (Ref.) & - & - & 1.000 (Ref.) & - & - \\
\hline yes & 2.027 & $1.291,3.183$ & 0.002 & 1.359 & $0.630,2.934$ & 0.434 \\
\hline TNM stage & & & 0.011 & & & 0.521 \\
\hline I & 1.000 (Ref.) & - & - & & & 0.238 \\
\hline II & 6.780 & $0.911,50.470$ & 0.062 & 4.067 & $0.396,41.773$ & 0.368 \\
\hline III & 13.027 & $1.783,95.153$ & 0.011 & 3.039 & $0.270,34.238$ & 0.536 \\
\hline IV & 10.208 & $1.340,77.791$ & 0.025 & 2.250 & $0.172,29.374$ & \\
\hline Pathology Grade & & & 0.166 & & & \\
\hline Well & 1.000 (Ref.) & - & - & & & \\
\hline Moderate & 1.581 & $0.976,2.559$ & 0.062 & & & \\
\hline $\begin{array}{l}\text { Poor/ } \\
\text { undifferentiated }\end{array}$ & 1.406 & $0.711,2.782$ & 0.328 & & & \\
\hline \multicolumn{7}{|l|}{ Gallstone } \\
\hline No & 1.000 (Ref.) & - & - & & & \\
\hline Yes & 1.134 & $0.726,1.771$ & 0.582 & & & \\
\hline \multicolumn{7}{|l|}{ Pathological type } \\
\hline adenocarcinoma & 1.000 (Ref.) & - & - & & & \\
\hline $\begin{array}{l}\text { Squamous/ } \\
\text { adenosquamous } \\
\text { carcinoma }\end{array}$ & 1.044 & $0.602,1.808$ & 0.879 & & & \\
\hline \multicolumn{7}{|l|}{ pStat-3 } \\
\hline $\begin{array}{l}\text { negative } \\
\text { expression }\end{array}$ & 1.000 (Ref.) & - & - & 1.000 (Ref.) & - & - \\
\hline $\begin{array}{r}\text { positive } \\
\text { expression }\end{array}$ & 1.991 & $1.240,3.197$ & 0.004 & 1.907 & $1.103,3.297$ & 0.021 \\
\hline \multicolumn{7}{|l|}{$\alpha v \beta 6$} \\
\hline Negative & 1.000 (Ref.) & - & - & 1.000 (Ref.) & - & - \\
\hline Positive & 2.174 & $1.383,3.419$ & 0.001 & 2.046 & $1.041,4.022$ & 0.038 \\
\hline
\end{tabular}


Ets-1 [30], STAT3 [12, 13], Smad3, AP-1 [33]and C/EBP $\alpha$ [12]could promote the initiation of integrin beta 6 expression.

We have known that the long-term chronic inflammation of gallbladder is a high risk factor for tumorigenesis of GBC, which could predispose inflammatory tissue to cancer development $[20,34]$. The continuous evidence of recent years has convinced us that IL-6/JAK/STAT3 pathway can play a definitive role in the transformation from inflammation to cancer for colorectum tumor [35] . Phosphorylation of Stat3 at Y705 could be facilitated by JAK family, and it is required for Stat3 homo- or hetero-dimerization, nuclear translocation, and DNA binding [17]. Moreover, cytokine-driven JAK/ STAT3 pathways are involved in cellular proliferation, differentiation, invasion, survival, and even inflammation and immune function of various human cancers $[8,11]$. Taken together, we could make a reasonable hypothesis that cytokine-driven JAK/STAT3 pathways may also mediate the expression of integrin beta6, which play an important role in tumor development and progression of GBC. Of course, our further work aims to demonstrate our hypotheses in cell lines and animal model. Promisingly, targeting the IL-6/JAK/STAT3 pathway may provide potential strategies for prevention and treatment of GBC.

\section{MATERIALS AND METHODS}

\section{Patients and follow-up}

We collected data and tumor specimens from patients diagnosed with gallbladder carcinoma(GBC) at Qilu Hospital of Shandong University between July 2006 and January 2013. All petients with GBC included in this study have received surgical resection(radical or palliative type) as the initial treatment modality without major perioperative complications, and also had enough archived tissue kept at Pathological Department of hospital. This resulted in a collection of tumor tissue from 97 patients, 34 males and 63 females with a median age of 61.3 years and an age range of 40-73 years. And for comparison, we also collected 76 benign gallbladder tissue samples including 40 peritumoral normal tissues taken from 97 GBC patients mentioned above, and the other 36 chronic cholecystitis tissues. These malignant and benign gallbladder carcinoma specimens were all formalin-fixed and paraffinembedded. The pathologic tumor-node-metastasis(TNM) classification was based on the criteria of the 7th edition American Joint Committee on Cancer(AJCC), and the tumor stage was confirmed by expert pathologists.

All the 97 patients with gallbladder carcinoma were followed up for 24 months after surgery through email or phones. Among those, 79(81.4\%) were confirmed GBC-associated death within 24 months of prognosis, 14 patients were alive beyond 60 months, and 4 were censored as their case follow up was discontinued or died of reasons other than GBC. The mean survival time for these patients was 14.4 months.
All patients or relatives signed an informed consent of this study. It was approved by the Ethics Committee of Qilu Hospital, Shandong University. The details of patients' characteristics have been listed in Table 1 .

\section{Antibodies and immunohistochemistry}

Immunohistochemistry was performed to evaluate the expression of pStat- 3 and $\alpha v \beta 6$ on $4 \mu \mathrm{m}$ thickness Paraffin-embedded tissue sections. The rabbit-anti-human monoclonal antibody EP2147Y (1:150,Abcam,Cambridge UK)against STAT3 (phospho Y705) and goat-anti-human polyclonal C-19 agaist integrin $\beta 6$ from Santa Cruz (1:200,Santa Cruz, USA) were applied respectively. HRP secondary antibodies and DAB kit were obtained from Zhongshan Golden Bridge (Beijing, China).

Then, immunohistochemical staining for the two markers was done as follows. The sections were deparaffinized and hydrated, and the heat induced antigen epitope retrieval was performed using microwave method, then and the slides were immersed in EDTA antigen retrieval solution $(\mathrm{pH} \mathrm{9.0)}$ for 20 min. Subsequently, $3 \%$ hydrogen peroxide was added to inhibit endogenous peroxidase activity. Next, antibodies STAT3 (1:150; Abcam,Cambridge, UK), integrin $\beta 6$ (1:200,Santa Cruz, USA) were applied to the sections, which were later incubated by either antibody at $4^{\circ} \mathrm{C}$ overnight. On the second day, tissue sections were incubated with universal IgG antibody-Fab-HRP polymer (Zhongshan Biotech, Beijing China)for 30 min; next, DAB and Hematoxylin were used to stain, and after sealed with neutral tree gum sequentially, sections were prepared for visualization under light microscope (Olympus Corp, Tokyo, Japan).

\section{Evaluation of pStat-3 and integrin $\alpha v \beta 6$ immunohistochemistry}

It is known that integrinav $\beta 6$ was expressed both in cytoplasm and on cellular membrane, mainly seen on the internal surface of the tumor epithelial cell membrane. And pStat-3 can Shuttle between the nucleus and the cytoplasm, which predominantly presents in the cytoplasm without stimuli, and accumulates in the nucleus upon stimulation. We evaluated the expression levels of pStat- 3 and integrin $\alpha v \beta 6$ via semi-quantitative method based on the average intensity and percentage of positively stained tumor cells. The score of intensity was graded as follows: 0 (no staining), 1 (weak staining, light yellow), 2 (moderate staining, yellow brown), and 3 (strong staining, brown). And the percentage of stained tumor cells was scored as $(0,0 \% ; 1,<20 \% ; 2$, $20 \sim 50 \% ; 3,51 \sim 75 \% ; 4,>75 \%)$. Then we defined the staining class according to the consensus results of both scores as follows: $<2$, negative expression; $2 \sim 4$, low (weak) expression, and $\geq 5$, high (strong) expression. And both low and high expressions were graded as $\alpha v \beta 6$ and pStat-3 positive. 


\section{Western blot analysis}

To further analyze and validate the expression of $\alpha v \beta 6$ and pStat-3 in GBC, western blot analysis was performed in 10 paired fresh primary tumor tissue and corresponding paracancerous normal tissue. And these paired fresh specimen were collected immediately after surgery between January 2011 and November 2012 and were stored at $-80^{\circ} \mathrm{C}$. All patients have confirmed the informed consent.

For Western Blot Analysis, total proteins extracted from fresh tissues were prepared in radio immunoprecipitation assay (RIPA) buffer (Beyotime, Jiangsu, China) including complete protease inhibitor cocktail (Roche Applied Science, Mannheim, Germany). Total proteins were separated by $10 \%$ SDSPAGE and then transferred to PVDF membranes. The membranes were blocked with 5\% skim milk in Trisbuffered saline with $0.1 \%$ Tween-20 (TBST) for $1 \mathrm{~h}$ at room temperature and then incubated with anti- pStat-3 (1:1000; Abcam, Cambridge, UK), anti-integrin $\beta 6$ (1:1500, Santa Cruz, USA) or anti-GAPDH (1:1000; Abcam, Cambridge, UK) antibodies overnight at $4^{\circ} \mathrm{C}$. After incubation with horseradish peroxidase conjugated anti-rabbit secondary antibodies for $1 \mathrm{~h}$, proteins were detected using enhanced chemiluminescence (Millipore, Billerica, MA).

\section{Statistical analysis}

Statistical analyses were performed with SPSS 13.0 software. The relationship among expression of pStat-3, integrin $\alpha v \beta 6$ and their clinicopathologic characteristics was examined using $\chi^{2}$ test or Fisher exact test. Survival analyses were carried out via the Kaplan-Meier method. And the Cox proportional hazard model was used to conduct univariate and Multivariate analysis. Besides, the relationship between $\mathrm{pStat}-3$ and integrin $\alpha \mathrm{v} \beta 6$ expression levels was evaluated by Spearman correlation. $P<0.05$ was considered statistically significant.

\section{CONCLUSION}

Our findings indicated that the expression levels of pSTAT3 and $\alpha v \beta 6$ are up-regulated in GBC tissue, which were associated with tumor progression and poor prognosis of patients. Besides, moderate-poor correlation existed between the expression of pSTAT3 and integrin av $\beta 6$, and molecular mechanism underlying them may contribute to the transformation from inflammation to cancer of GBC, which may provide a potential therapeutic approach to treat this disease.

\section{ACKNOWLEDGMENTS AND GRANT SUPPORT}

This study was supported by the research Grants from Key Technologies R \& D Program of Shandong Provnice(2015GSF118091).

\section{CONFLICTS OF INTEREST}

None.

\section{Authors' contributions}

LE was responsible for designing of the study and critical review of manuscript; LE, WN, XZ and ZMwere responsible for performing of the study, literature research and manuscript writing; WY, WX, ZC, WB, LZ, HJ and WJ were responsible for data acquisition, and LB, SQ, PC were for data analysis. All authors approved the final version of the manuscript.

\section{REFERENCES}

1. Jemal A, Siegel R, Ward E, Hao Y, Xu J, Murray T and Thun MJ. Cancer statistics, 2008. CA Cancer J Clin. 2008; 58:71-96.

2. Groot Koerkamp B and Fong Y. Outcomes in biliary malignancy. J Surg Oncol. 2014; 110:585-591.

3. Oh TG, Chung MJ, Bang S, Park SW, Chung JB, Song SY, Choi GH, Kim KS, Lee WJ and Park JY. Comparison of the sixth and seventh editions of the AJCC TNM classification for gallbladder cancer. J Gastrointest Surg. 2013; 17:925-930.

4. Jayaraman S and Jarnagin WR. Management of gallbladder cancer. Gastroenterol Clin North Am. 2010; 39:331-342, x.

5. Rakic M, Patrlj L, Kopljar M, Klicek R, Kolovrat M, Loncar B and Busic Z. Gallbladder cancer. Hepatobiliary Surg Nutr. 2014; 3:221-226.

6. Hart J, Modan B and Shani M. Cholelithiasis in the aetiology of gallbladder neoplasms. Lancet. 1971; 1:1151-1153.

7. Shrikhande SV, Barreto SG, Singh S, Udwadia TE and Agarwal AK. Cholelithiasis in gallbladder cancer: coincidence, cofactor, or cause! Eur J Surg Oncol. 2010; 36:514-519.

8. Han J and Theiss AL. Stat3: friend or foe in colitis and colitis-associated cancer? Inflamm Bowel Dis. 2014; 20:2405-2411.

9. Yu H, Kortylewski M and Pardoll D. Crosstalk between cancer and immune cells: role of STAT3 in the tumour microenvironment. Nat Rev Immunol. 2007; 7:41-51.

10. Niwa Y, Kanda H, Shikauchi Y, Saiura A, Matsubara K, Kitagawa T, Yamamoto J, Kubo T and Yoshikawa H. Methylation silencing of SOCS-3 promotes cell growth and migration by enhancing JAK/STAT and FAK signalings in human hepatocellular carcinoma. Oncogene. 2005; 24:6406-6417.

11. Thomas SJ, Snowden JA, Zeidler MP and Danson SJ. The role of JAK/STAT signalling in the pathogenesis, prognosis and treatment of solid tumours. Br J Cancer. 2015; 113:365-371.

12. Xu M, Chen X, Yin H, Yin L, Liu F, Fu Y, Yao J and Deng $\mathrm{X}$. Cloning and characterization of the human integrin beta6 gene promoter. PLoS One. 2015; 10:e0121439. 
13. Azare J, Leslie K, Al-Ahmadie H, Gerald W, Weinreb PH, Violette SM and Bromberg J. Constitutively activated Stat3 induces tumorigenesis and enhances cell motility of prostate epithelial cells through integrin beta 6. Mol Cell Biol. 2007; 27:4444-4453.

14. Seguin L, Desgrosellier JS, Weis SM and Cheresh DA. Integrins and cancer: regulators of cancer stemness, metastasis, and drug resistance. Trends Cell Biol. 2015; 25:234-240.

15. Hynes RO. Integrins: bidirectional, allosteric signaling machines. Cell. 2002; 110:673-687.

16. Barczyk M, Carracedo S and Gullberg D. Integrins. Cell Tissue Res. 2010; 339:269-280.

17. Bates RC, Bellovin DI, Brown C, Maynard E, Wu B, Kawakatsu H, Sheppard D, Oettgen P and Mercurio AM. Transcriptional activation of integrin beta6 during the epithelial-mesenchymal transition defines a novel prognostic indicator of aggressive colon carcinoma. J Clin Invest. 2005; 115: 339-347.

18. Cantor D, Slapetova I, Kan A, McQuade LR and Baker MS. Overexpression of alphavbeta6 integrin alters the colorectal cancer cell proteome in favor of elevated proliferation and a switching in cellular adhesion that increases invasion. $\mathrm{J}$ Proteome Res. 2013; 12:2477-2490.

19. Bates RC. The alphaVbeta6 integrin as a novel molecular target for colorectal cancer. Future Oncol. 2005; 1:821-828.

20. Hundal R and Shaffer EA. Gallbladder cancer: epidemiology and outcome. Clin Epidemiol. 2014; 6:99-109.

21. Bandyopadhyay A and Raghavan S. Defining the role of integrin alphavbeta6 in cancer. Curr Drug Targets. 2009; 10:645-652.

22. Thomas GJ, Nystrom ML and Marshall JF. Alphavbeta6 integrin in wound healing and cancer of the oral cavity. $\mathrm{J}$ Oral Pathol Med. 2006; 35:1-10.

23. Ahmed N, Niu J, Dorahy DJ, Gu X, Andrews S, Meldrum CJ, Scott RJ, Baker MS, Macreadie IG and Agrez MV. Direct integrin alphavbeta6-ERK binding: implications for tumour growth. Oncogene. 2002; 21:1370-1380.

24. Zhao-Yang Z, Ke-Sen X, Qing-Si H, Wei-Bo N, Jia-Yong W, Yue-Tang M, Jin-Shen W, Guo-Qiang W, Guang-Yun Y and Jun N. Signaling and regulatory mechanisms of integrin alphavbeta 6 on the apoptosis of colon cancer cells. Cancer Lett. 2008; 266:209-215.
25. Gu X, Niu J, Dorahy DJ, Scott R and Agrez MV. Integrin alpha(v)beta6-associated ERK2 mediates MMP-9 secretion in colon cancer cells. Br J Cancer. 2002; 87:348-351.

26. Liu S, Wang J, Niu W, Liu E, Peng C, Lin P, Wang B, Khan AQ, Gao H, Liang B, Shahbaz M and Niu J. The beta6integrin-ERK/MAP kinase pathway contributes to chemo resistance in colon cancer. Cancer Lett. 2013; 328:325-334.

27. Levy DE and Lee CK. What does Stat 3 do? J Clin Invest. 2002; 109:1143-1148.

28. Ernst M, Thiem S, Nguyen PM, Eissmann M and Putoczki TL. Epithelial gp130/Stat3 functions: an intestinal signaling node in health and disease. Semin Immunol. 2014; 26:29-37.

29. Fichtner-Feigl S, Kesselring R and Strober W. Chronic inflammation and the development of malignancy in the GI tract. Trends Immunol. 2015.

30. Bates RC, Bellovin DI, Brown C, Maynard E, Wu B, Kawakatsu H, Sheppard D, Oettgen P and Mercurio AM. Transcriptional activation of integrin beta6 during the epithelial-mesenchymal transition defines a novel prognostic indicator of aggressive colon carcinoma. J Clin Invest. 2005; 115:339-347.

31. Wang B, Wang W, Niu W, Liu E, Liu X, Wang J, Peng C, Liu S, Xu L, Wang L and Niu J. SDF-1/CXCR4 axis promotes directional migration of colorectal cancer cells through upregulation of integrin alphavbeta6. Carcinogenesis. 2014; 35:282-291.

32. Enyu L, Zhengchuan N, Jiayong W, Benjia L, Qi S, Ruixi Q, Cheng P, Khan AQ, Wei S and Jun N. Integrin beta6 can be translationally regulated by eukaryotic initiation factor 4E: Contributing to colonic tumor malignancy. Tumour Biol. 2015.

33. Sullivan BP, Kassel KM, Manley S, Baker AK and Luyendyk JP. Regulation of transforming growth factorbeta1-dependent integrin beta 6 expression by p38 mitogenactivated protein kinase in bile duct epithelial cells. J Pharmacol Exp Ther. 2011; 337:471-478.

34. Rashid A, Ueki T, Gao YT, Houlihan PS, Wallace C, Wang BS, Shen MC, Deng J and Hsing AW. K-ras mutation, p53 overexpression, and microsatellite instability in biliary tract cancers: a population-based study in China. Clin Cancer Res. 2002; 8:3156-3163.

35. Wang SW and Sun YM. The IL-6/JAK/STAT3 pathway: potential therapeutic strategies in treating colorectal cancer (Review). Int J Oncol. 2014; 44:1032-1040. 